\title{
ДИАГНОСТИКА ДОКЛИНИЧЕСКИХ ПРИЗНАКОВ ОПТИЧЕСКОЙ НЕЙРОПАТИИ ПРИ ЭНДОКРИННОЙ ОФТАЛЬМОПАТИИ
}

\author{
Саакян С.В., Пантелеева О.Г., Мякошина Е.Б., Сирмайс О.С. \\ ФГБУ «НМИЦ ГБ им. Гельмгольца» Минздрава России Москва
}

Одним из самых частых и грозных осложнений эндокринной офтальмопатии (ЭОП) является оптическая нейропатия $(\mathrm{OH})$, которая создает реальную угрозу потери зрительных функций и ведет к инвалидизации больных. В последние десятилетия в офтальмологии активно применяют метод оптической когерентной томографии (ОКТ), позволяющий выявить самые ранние изменения со стороны диска зрительного нерва (ДЗН) и макулы при ОН на микронном уровне и вовремя начать необходимое лечение.

ЦЕЛЬ: ВЫявить доклинические признаки ОН с помощью ОКТ.

МАТЕРИАЛЫ И МЕТОДЫ: проведено обследование 70 пациентов (140 глаз) с диагнозом ЭОП, из них 40 человек (80 глаз) с диагностированной рефрактерной формой ЭОП и 30 больных с первично выявленной ЭОП в неактивной и активной стадиях. Диагноз рефрактерной формы ЭОП устанавливали в случае, если больной не отметил улучшения или произошло ухудшение состояния глаз и орбит после проведенной глюкокортикоидной терапии. Для определения морфометрических параметров ДЗН и сетчатки использован спектральный оптический когерентный томограф (COKT) «SOCT, Copernicus, 4.2» (Польша). Результаты: Проведенная компьютерная периметрия показала, что у всех больных, вне зависимости от степени активности ЭОП и высоких зрительных функций, выявлены признаки ОН, в связи с чем выделено 3 группы больных по стадии развития оптической нейропатии по мере ее утяжеления (латентная $\mathrm{OH}(\mathrm{Vis}=0,9-1,0)$, развитая (Vis=0,2-0,8) и далеко зашедшая $\mathrm{OH}(\mathrm{Vis}=0,01-0,1)$ ). Отмечено увеличение средней толщины слоя нервных волокон сетчатки в перипапиллярной зоне при далеко зашедшей ОН до 167,44 34,33 мкм, по сравнению с другими стадиями ОН, в которых данный показатель составил

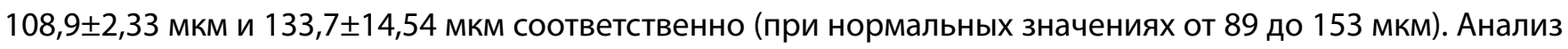
толщины сетчатки в макулярной зоне также показал ееувеличение по мереутяжеления $\mathrm{OH}(241,2 \pm 5,73$ мкм, $316,9 \pm 32,21$ мкм, 346,9 $\pm 85,48$ мкм, при норме 168-239 мкм). Вне зависимости от остроты зрения у всех больных отмечено увеличение объема и площади нейроретинального пояска головки зрительного не-

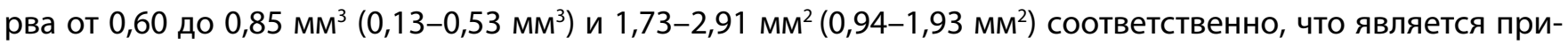
знаком наличия отека ДЗН.

ВЫВОдЫ: анализ результатов ОКТ заднего отрезка глаза позволила выявить доклинические признаки ОН на микронном уровне включающие: увеличение толщины слоя нервных волокон сетчатки в перипапиллярной зоне, увеличения площади нейроретинального пояска, увеличения объема нейроретинального пояска, увеличения толщины сетчатки макулярной зоны. Таким образом использование ОКТ в качестве неинвазивного и безопасного метода в диагностике латентной стадии ОН при ЭОП позволит своевременно начинать соответствующее лечение, что в свою очередь снизит риск развития необратимой слепоты. 